Editorial

\title{
Energy Efficiency in Smart Homes and Smart Grids
}

\author{
Anna Fensel ${ }^{1, *}$ and Juan Miguel Gómez Berbís ${ }^{2}$ \\ 1 Semantic Technology Institute (STI) Innsbruck, Department of Computer Science, University of Innsbruck, \\ Technikerstr. 21a, 6020 Innsbruck, Austria \\ 2 Software Architect Group, Department of Computer Science, Carlos III University of Madrid, Av. de la \\ Universidad 30, Leganés, 28911 Madrid, Spain; juanmiguel.gomez@uc3m.es \\ * Correspondence: anna.fensel@sti2.at; Tel.: +43-512-507-53720
}

Citation: Fensel, A.; Gómez Berbís, J.M. Energy Efficiency in Smart Homes and Smart Grids. Energies 2021, 14, 2054. https://doi.org/ 10.3390/en14082054

Received: 19 January 2021

Accepted: 6 April 2021

Published: 8 April 2021

Publisher's Note: MDPI stays neutral with regard to jurisdictional claims in published maps and institutional affiliations.

Copyright: (c) 2021 by the authors. Licensee MDPI, Basel, Switzerland. This article is an open access article distributed under the terms and conditions of the Creative Commons Attribution (CC BY) license (https:// creativecommons.org/licenses/by/ $4.0 /)$.
Here, we overview the Energies journal special issue that is dedicated to the topic of "Energy Efficiency in Smart Homes and Smart Grids" (https: / /www.mdpi.com/journal/ energies/special_issues/Smart_Home_Grid (accessed on 5 April 2021)) and the papers published in it. The call for papers looking for new directions in the topic of "Energy Efficiency in Smart Homes and Smart Grids" was open in 2020, and the text announcing the special issue was as follows: "This Special Issue focuses on advancements in the energy efficiency of smart homes and smart grids. This encompasses smart homes, smart grids, smart cities and villages, ICT solutions for efficient energy consumption, as well as energy production and distribution. This Special Issue is especially interested in receiving highquality, unpublished submissions that focus on advancing the technologies for sensor infrastructures, knowledge management, and engineering, as well as user engagement: in particular, energy savings should take place without a decrease in residents' quality of life. We are interested in back-end technologies, such as for the predictive maintenance and optimization of energy distribution and consumption, as well as in front-end technologies, such as end-user interfaces, gamification, and techniques facilitating behavior change. Further, data are playing an increasingly important role in energy efficiency, and are gaining a leading role in various domains, such as future building certification, smart grid and meter management, and predictive maintenance. Specifically, we are looking into the combination of machine learning and semantic techniques, for example, combining them in order to create high-quality knowledge graphs in the energy efficiency domain for smart homes and smart grids".

The applied keywords were as follows:

- Intelligent Cyber-Physical ICT Infrastructures: Smart Home, Smart Village, Smart City.

- Smart Homes and Energy Efficiency.

- Semantics and Ontologies for Smart Homes and Smart Grids.

- Smart Home and Smart Grid Data Management with Knowledge Graphs.

- Smart Metering.

- Building Information Management and Energy Efficiency.

- Predictive Maintenance.

- Smart Energy Grids.

- $\quad$ Energy-Efficient Data Centers.

- RFID and Sensors, Intelligent Sensors.

- $\quad$ Embedded Computing Systems.

- Cloud Computing in Smart Home Technology.

- Machine Learning for Energy Efficiency.

- Energy Data Collection and Processing.

- Energy Data Repository and Management in Cloud.

- Smart Building and City Data Management.

- Semantic Rules, Policies, and Context-Awareness in Smart Buildings.

- Behavioral Change in Smart Cities. 
- Gaming for Energy Saving.

- Energy Efficiency Education.

- Ambient Intelligence, Human-Computer/ Human-Machine/ Human-Device Interface.

- Physical and Conceptual Modeling of Cyber-Physical Environments.

- Human Factors, Ethics, and Usability.

- Ubiquitous and Pervasive Computing Concerns.

- Smart Management of Home Appliances.

- Management of Home Energy Concerns.

- Context Awareness and Autonomous Computing.

- Residential Networks and Services.

- Mobile Services.

- Social, Policy, Privacy, Security Concerns.

- Middleware Design and Support for Smart Home.

- Guidelines and Policy for Future Energy Efficiency Building Certification.

- Innovative Smart Home Applications and Services.

- Smart Environment Monitoring and Control.

The special issue resulted in five published papers as follows. Managing and operating on data with $\mathrm{AI}$ techniques such as with machine learning and knowledge graphs remained the focus of the attention of the special issue. The papers have been focusing on looking into the specific details and techniques in smart grids [1], systems connecting smart grids and smart homes [2], as well as smart homes [3]. Furthermore, the physical characteristics of the systems and accounting of their features continue to play an important role in the addressed topic. In this issue, the impact of various characteristics of windows in buildings has been comprehensively overviewed by Cannavale et al. [4]. On the other hand, addressing the matters of energy-efficient buildings have been also shown from a very different, economic perspective [5].

Author Contributions: Conceptualization, A.F. and J.M.G.B.; investigation, A.F. and J.M.G.B.; writing-original draft preparation, A.F.; writing-review and editing, A.F. and J.M.G.B.; supervision, A.F. and J.M.G.B.; project administration, A.F. and J.M.G.B.; funding acquisition, A.F.; J.M.G.B. Both authors have read and agreed to the published version of the manuscript.

Funding: This research was co-funded by Interreg Österreich-Bayern 2014-2020 programme project KI-Net: Bausteine für KI-basierte Optimierungen in der industriellen Fertigung (AB 292). This work is also supported by the ITEA3 OPTIMUM project and ITEA3 SCRATCH project, all of them funded by the Centro Tecnológico de Desarrollo Industrial (CDTI), Spain.

Institutional Review Board Statement: Not applicable.

Informed Consent Statement: Not applicable.

Conflicts of Interest: The authors declare no conflict of interest.

\section{References}

1. Hafeez, G.; Alimgeer, K.S.; Wadud, Z.; Shafiq, Z.; Khan, M.U.A.; Khan, I.; Khan, F.A.; Derhab, A. A Novel Accurate and Fast Converging Deep Learning-Based Model for Electrical Energy Consumption Forecasting in a Smart Grid. Energies 2020, 13, 2244. [CrossRef]

2. Yoon, A.-Y.; Kang, H.-K.; Moon, S.-I. Optimal Price Based Demand Response of HVAC Systems in Commercial Buildings Considering Peak Load Reduction. Energies 2020, 13, 862. [CrossRef]

3. Machorro-Cano, I.; Alor-Hernández, G.; Paredes-Valverde, M.A.; Rodríguez-Mazahua, L.; Sánchez-Cervantes, J.L.; OlmedoAguirre, J.O. HEMS-IoT: A Big Data and Machine Learning-Based Smart Home System for Energy Saving. Energies 2020, 13, 1097. [CrossRef]

4. Cannavale, A.; Ayr, U.; Fiorito, F.; Martellotta, F. Smart Electrochromic Windows to Enhance Building Energy Efficiency and Visual Comfort. Energies 2020, 13, 1449. [CrossRef]

5. Orynycz, O.; Tucki, K. Technology Management Leading to a Smart System Solution Assuring a Decrease of Energy Consumption in Recreational Facilities. Energies 2020, 13, 3425. [CrossRef] 